\title{
Racial and Ethnic Disparities in Knowledge About Hepatitis C
}

\author{
Stacey B. Trooskin ${ }^{1}$, Maricruz Velez ${ }^{1}$, Simona Rossi ${ }^{1}$, Steven K. Herrine ${ }^{1}$, Robert Winn ${ }^{2}$, \\ David J. Axelrod ${ }^{3}$, A. Scott McNeal ${ }^{4}$ and Victor J. Navarro ${ }^{*}, 1$ \\ ${ }^{I}$ Thomas Jefferson University, Division of Gastroenterology and Hepatology, 132 South $10^{\text {th }}$ Street, Suite 480 Main \\ Building, Philadelphia, PA 19107, USA \\ ${ }^{2}$ Thomas Jefferson University, Department of Family Medicine, Philadelphia, PA, USA \\ ${ }^{3}$ Thomas Jefferson University, Division of Internal Medicine, Philadelphia, PA, USA \\ ${ }^{4}$ Delaware Valley Community Health Inc., Philadelphia, PA, USA
}

\begin{abstract}
The aim of this study was to characterize knowledge of $\mathrm{HCV}$, specifically in an urban, minority population.
Methods: New patients, 18 or older, were prospectively enrolled at four primary care practices in Philadelphia. Demographics were ascertained and a survey was administered, querying HCV knowledge. Log-linear regression was used to assess the relationship between race and knowledge, measured by percentage of correct answers.

Results: There were 1657 patients enrolled in this study. Whites were most likely to choose the correct answers; Hispanics were least likely to answer questions correctly, irrespective of age and education level $(p<0.0001)$. US born Hispanics (including those born in PR) and Blacks had a similar HCV knowledge. Non-US born Hispanics knew significantly less than their US born counterparts ( $p=.0005)$, even after adjusting for education and age. Non-US born Hispanics living in the US for 5 years or more had greater knowledge of HCV than individuals who have been living in the US for less than 5 years.
\end{abstract}

Conclusion: In this urban population, Blacks and Hispanics knew significantly less than whites about HCV; Hispanics born outside the United States and PR have even greater knowledge deficits.

\section{INTRODUCTION}

Hepatitis $\mathrm{C}$ virus (HCV) infection is the most common chronic bloodborne infection in the United States with an estimated 2.7 million persons infected $[1,2]$. Acute onset of hepatitis $\mathrm{C}$ is rarely identified and chronic infection is often asymptomatic, causing many individuals to be unaware of their infection [3]. The National Institutes of Health recommends that the American public be educated regarding the transmission of HCV so that potentially infected individuals may be more likely to recognize their risk [4]. In order to develop appropriate educational interventions, it is important to assess the current level of knowledge about HCV. Since minorities, particularly African Americans, are disproportionately affected by $\mathrm{HCV}$ [1, 5-7], particular attention should be given to the assessment of HCV knowledge in these groups.

Buffington and colleagues demonstrated that overall knowledge of HCV related issues, as assessed in a mailed survey, is poor. They found that although blacks were more likely to report having heard of hepatitis $\mathrm{C}$ virus than whites or Hispanics, blacks were less likely to respond accurately to multiple statements regarding hepatitis $\mathrm{C}$ risks and prevention [8]. In an attempt to further investigate this issue, we assessed HCV related knowledge in the context of a prospective study conducted in a racially and ethnically diverse urban population of patients seeking primary care.

*Address correspondence to this author at the Thomas Jefferson University, Division of Gastroenterology and Hepatology, 132 South $10^{\text {th }}$ Street, Suite 480 Main Building, Philadelphia, PA 19107, USA;

E-mail: victor.navarro@jefferson.edu

\section{MATERIALS AND METHODOLOGY}

A prospective cohort study was conducted among patients being seen for the first time by primary care providers at study sites within the greater Philadelphia area. Approval from the Thomas Jefferson University Institutional Review Board was obtained. These practices included two federally qualified health clinics serving predominantly minority populations and two university-based primary care practices, one of which was a family medicine practice and the other was an internal medicine practice. Each of the four study sites served a somewhat different population. Community clinic \#1 serves a predominantly Hispanic population (85\%), of which approximately $25 \%$ are undocumented immigrants. Community clinic \#2 serves a predominantly black population $(65-70 \%)$. The majority of the patients attending the two community clinics are either uninsured or are covered by a Medicaid HMO. The two university-based practices serve racially diverse populations. Approximately $45 \%$ of the patients attending the Internal Medicine university-based practice are black, and the majority of the patients attending the practice have traditional insurance. Approximately $60 \%$ of the patients attending the Family Medicine university-based practice are black and roughly half of all of the patients attending the practice have traditional insurance.

\section{Participants and Recruitment}

We included all patients, 18 or older, who had not been seen in the practice for 5 years or more, regardless of the reason for their visit. Informed consent was obtained in English or Spanish and participants were given the questionnaire, also available in English or Spanish, to complete while 
waiting to see their physician. Questionnaires were then collected by the study staff. Bilingual research assistants enrolled participants and distributed the questionnaires. The research assistant remained available for individuals unable to see or read the questions themselves.

From the 2,010 potentially eligible patients, $8 \%$ refused study enrollment and 111 either did not complete study procedures or had been seen at the practice within the previous 5 years. Thus, there were a total of 1738 evaluable patients in the study $(86 \%)$. Race/ethnicity information was not reported or marked as "other" for 81 participants. Individuals born outside of the United States were asked the year in which they immigrated to the US in a follow-up phone interview.

\section{Questionnaire}

Questions were modeled after those used by the Centers for Disease Control as part of their follow-up for patients who tested positive for $\mathrm{HCV}$ in the National Health and $\mathrm{Nu}-$ trition Examination Survey (NHANES, Alter, M personal communication, June 2004). There were eleven items with three possible responses; "True", "False" or "I don't know". This survey instrument also collected basic demographic information including sex, age, annual household income, education level, and insurance status. Patients were asked to identify themselves as Caucasian or white (non-Hispanic), Latino or Hispanic (including country of birth), black or African American, Asian or Pacific Islander, or "Other". Racially/ ethnically mixed subjects were classified accordingly: Individuals self identifying as part Hispanic were classified as Hispanic. Individuals who identified themselves as part black and part white were classified as black.

\section{Data Analysis}

\section{Development of Composite Scores to Assess Knowledge}

The percentage of incorrect answers was calculated for each individual. Responses were regarded as "correct" if they were in agreement with the prevailing literature on the subject [4]. The response "I don't know" was combined with the incorrect answers for purposes of scoring. Comparisons between racial and ethnic groups were made to determine if there were significant differences in percentage of correct responses by race. For analyses where lack of knowledge was treated as the dependent variable, a higher mean score signifies that an individual was more likely to answer a question incorrectly or choose "I don't know". The statement "You can get hepatitis C by having sex with someone who has hepatitis C" was included in the questionnaire as an exploratory question since scientific evidence indicates that it confers a small but unknown risk. This question was not included in the analysis since less than $8 \%$ of respondents answered the question correctly irrespective of race.

\section{Associations Between Misconceptions Regarding HCV and Race/Ethnicity}

The primary study outcome was the percentage of incorrect answers to a series of HCV-related questions. Log-linear regression was used to assess if race/ethnicity was associated with $\mathrm{HCV}$ knowledge after controlling for the independent effects of education, age, sex and insurance status. A gamma distribution was assumed. This approach takes into account the skewed distribution of the outcome measurements. In the log-linear models, a higher score reflects increasing knowledge deficit with respect to $\mathrm{HCV}$. The likelihood ratio test was used to determine the overall significance of each covariate.

Additional analyses were conducted for Hispanic subpopulations, by comparing those born in the United States, including Puerto Rico, with those born elsewhere. The purpose of this analysis was to explore the possibility that county of birth and period of residency in the U.S. may affect knowledge.

\section{RESULTS}

\section{Study Population}

A total of 1657 patients with available race and ethnicity information were included in the study. Five-hundred and seven participants identified themselves as being Latino or Hispanic, 691 (42\%) as white, and 459 (28\%) as black or African American. Of those patients that identified themselves as being of Hispanic origin (30\%), 255 were born in Puerto Rico or mainland United States. The remaining 250 participants were born in 21 other countries. Two individuals did not identify their country of origin. Population characteristics are displayed in Table 1. Nineteen percent of participants had not completed high school and $40 \%$ had an annual household income of less than $\$ 15,000$. Overall, the Hispanic group had fewer males, was less educated, was less likely to have insurance, and was poorer than the other groups.

\section{Socioeconomic and Demographic Associations with Mis- conceptions About HCV}

The average score obtained for the HCV knowledge scale overall was $40 \%$ incorrect (SD 27\%). The knowledge score differed by race with whites responding to $29 \%$ of the items incorrectly, and blacks and Hispanics responding to $42 \%$ and $55 \%$ of the items incorrectly $(\mathrm{p}<0.05)$. Hispanics born outside the US and Puerto Rico were more likely to respond to the items incorrectly $(60 \%)$ as compared to Hispanics born in the US and Puerto Rico (48\%). Table 2 displays the percentage of individuals of each race/ethnicity that responded to each item incorrectly. Thirty percent or less of the white patients answered eight of eleven questions incorrectly. However, more than $65 \%$ of whites, and even more blacks and Hispanics responded incorrectly to the item regarding the availability of a vaccine for hepatitis $\mathrm{C}$. In addition more than $50 \%$ of white patients were unaware that hepatitis $\mathrm{C}$ is not transmitted by kissing and $39 \%$ of whites were unaware that $\mathrm{HCV}$ could be transmitted perinatally.

Both race and education were independently associated with HCV knowledge with lower levels of education being associated with a greater number of incorrect answers (data not shown) $(\mathrm{p}<0.0001)$. The multivariate model demonstrated that compared to whites Hispanics (OR $1.795 \% \mathrm{CI}$ $(1.5,2.0))$ and Blacks (OR $1.395 \%$ CI $(1.2,1.6))$ were more likely to have misconceptions regarding $\mathrm{HCV}$ after adjusting for education, age, and sex.

One hundred and eighty five Hispanics provided information regarding the number of years in which they've 
Table 1. Population Characteristics by Race/Ethnicity $(n=1657)$

\begin{tabular}{|c|c|c|c|}
\hline & White $(\mathrm{N}=691)$ & Black $(\mathrm{N}=459)$ & Hispanic $(\mathrm{N}=507)$ \\
\hline \multicolumn{4}{|l|}{ Age } \\
\hline 24 years old or younger & $21 \%$ & $20 \%$ & $25 \%$ \\
\hline 25 to 30 years old & $24 \%$ & $16 \%$ & $20 \%$ \\
\hline 31 to 40 years old & $20 \%$ & $25 \%$ & $25 \%$ \\
\hline 41 to 50 years old & $15 \%$ & $21 \%$ & $16 \%$ \\
\hline 50 years or older & $20 \%$ & $17 \%$ & $13 \%$ \\
\hline Male & $47 \%$ & $41 \%$ & $39 \%^{*}$ \\
\hline \multicolumn{4}{|l|}{ Education } \\
\hline Less than High School Diploma & $3.0 \%$ & $16 \% \neq$ & $41 \%$ \\
\hline Completed High School, but no Bachelor's degree & $32 \%$ & $70 \% \neq$ & $41 \%$ \\
\hline 4 year college graduate or graduate school & $66 \%$ & $14 \%$ & $18 \%$ \\
\hline \multicolumn{4}{|l|}{ Annual Household Income* } \\
\hline$<\$ 15,000$ & $17 \%$ & $39 \% \neq$ & $70 \%$ \\
\hline$\$ 15,000-\$ 30,000$ & $12 \%$ & $27 \%^{\star}$ & $17 \%^{\star}$ \\
\hline$\$ 30,000-\$ 50,000$ & $20 \%$ & $23 \%+$ & $8 \%{ }^{*}$ \\
\hline$\$ 50,000-\$ 100,000$ & $28 \%$ & $8 \% \neq$ & $3 \%$ \\
\hline$>\$ 100,000$ & $23 \%$ & $3 \%$ & $1 \%{ }^{\star}$ \\
\hline Insured (includes Medicaid) & $96 \%$ & $77 \% \neq$ & $41 \%^{\bullet}$ \\
\hline
\end{tabular}

$20 \%$ of the data for this field are missing.

Comparisons made by multiple chi-squares:

${ }^{7}$ Significantly different from Hispanics $(\mathrm{p}<0.05)$.

• Significantly different from white $(\mathrm{p}<0.05)$.

${ }^{\ddagger}$ Significantly different from both Hispanics and whites $(\mathrm{p}<0.05)$

Table 2. Percent Incorrect for Each Item by Race/Ethnicity

\begin{tabular}{|c|c|c|c|c|c|}
\hline \multirow[b]{2}{*}{ Statement (Correct Answer) } & \multirow[b]{2}{*}{$\begin{array}{l}\text { White } \\
\text { N=691 }\end{array}$} & \multirow[b]{2}{*}{$\begin{array}{c}\text { Black } \\
N=459\end{array}$} & \multicolumn{3}{|c|}{ Hispanic } \\
\hline & & & $\begin{array}{l}\text { Overall } \\
\mathbf{N}=507 *\end{array}$ & $\begin{array}{l}\text { US Born } \\
\mathbf{N}=\mathbf{2 5 5}\end{array}$ & $\begin{array}{c}\text { Non-US Born } \\
\mathbf{N}=\mathbf{2 5 0}\end{array}$ \\
\hline Patients should avoid alcohol (True) & $5 \%$ & $8 \%^{*}$ & $10 \%^{\bullet}$ & $7 \%$ & $13 \%^{+}$ \\
\hline The virus can stay for life (True) & $30 \%$ & $49 \%^{\ddagger}$ & $59 \%^{*}$ & $51 \%$ & $67 \%^{+}$ \\
\hline HCV can damage the liver (True) & $30 \%$ & $43 \%^{\neq}$ & $50 \%^{*}$ & $42 \%$ & $58 \%^{+}$ \\
\hline Patients can look/feel well (True) & $24 \%$ & $34 \%^{\neq}$ & $65 \%^{*}$ & $49 \%$ & $81 \%^{+}$ \\
\hline There is a vaccine for HCV (False) & $66 \%$ & $83 \%^{\ddagger}$ & $91 \%^{*}$ & $87 \%$ & $94 \%+$ \\
\hline Injecting drugs can transmit HCV (True) & $20 \%$ & $32 \%^{\neq}$ & $46 \%^{*}$ & $39 \%$ & $50 \%{ }^{+}$ \\
\hline Shaking hands can transmit HCV (False) & $16 \%$ & $26 \%^{\ddagger}$ & $37 \%^{*}$ & $35 \%$ & $39 \%$ \\
\hline Kissing can transmit HCV (False) & $51 \%$ & $72 \%^{\neq}$ & $80 \%^{\bullet}$ & $80 \%$ & $79 \%$ \\
\hline A needlestick can transmit HCV (True) & $11 \%$ & $21 \%^{\ddagger}$ & $31 \%^{*}$ & $22 \%$ & $41 \%^{+}$ \\
\hline A newborn can get HCV if the mother is infected (True) & $39 \%$ & $45 \%{ }^{\top}$ & $57 \%^{*}$ & $50 \%$ & $63 \%^{+}$ \\
\hline An infected co-worker can transmit HCV (False) & $25 \%$ & $41 \%^{\ddagger}$ & $48 \%^{\bullet}$ & $45 \%$ & $52 \%$ \\
\hline Overall Mean Score & $29 \%$ & $42 \%^{\neq}$ & $53 \%{ }^{\star}$ & $48 \%$ & $60 \%{ }^{+}$ \\
\hline
\end{tabular}

${ }^{+}$Significantly different from US-born Hispanics $(\mathrm{p}<0.05)$

- Significantly different from white $(\mathrm{p}<0.05)$.

${ }^{\ddagger}$ Significantly different from both Hispanics overall and whites.

${ }^{\top}$ Significantly different from Hispanics overall.

* Country of origin for two Hispanic patients is unknown. 
resided in the U.S. Those Hispanics born outside the United States had a greater number of misconceptions regarding $\mathrm{HCV}$ than US-born Hispanics (including Puerto Rico) (OR $1.2,95 \%$ CI $(1.1,1.4))$. This difference remained significant after adjusting for education, age and sex. Misconceptions regarding $\mathrm{HCV}$ decreased with an increasing number of years Hispanic immigrants reported living in the United States (Fig. 1). For example, individuals who lived in the US for 20 or more years $(n=62)$ had a mean score of $51.6 \%$ incorrect on the knowledge scale. Hispanics living in the US for 10 to 19 years and 5 to 9 years had mean scores of $53.5 \%$ and $57.7 \%$ incorrect respectively. Lastly, Hispanics living in the US for less than 5 years had a mean score of $63.3 \%$ incorrect. After adjusting for age, education and sex in a multivariate model, Hispanic individuals born outside the US who immigrated to the US more than 5 years ago were less likely to have misconceptions regarding HCV than individuals who had been living in the US for 5 years or less (OR $0.8595 \% \mathrm{CI}(0.73,0.97))$.

Fig. (1). HCV knowledge and years living in the US among Hispanic immigrants $\left(\mathrm{N}=185^{*}\right)$.

*Of the 248 foreign born Hispanics, 63 were lost to follow-up and thus did not report year of immigration.

\section{DISCUSSION AND CONCLUSION}

The aim of this prospective study was to assess differences in knowledge about HCV in a racially diverse population. We ascertained patients from urban primary care practices in Philadelphia, as the clientele from these clinics was expected to have large numbers of minority patients. We found that overall, knowledge regarding $\mathrm{HCV}$ is less than optimal, and minorities knew significantly less than whites about nearly all aspects of HCV. This assessment comprised questions on transmission, natural history, treatment, and the availability of a vaccine. Given the heterogeneity of Hispanic Americans, we dichotomized this group based on U.S. birth status. We found that individuals born outside the United States and Puerto Rico had greater knowledge deficits than their non-Hispanic U.S. counterparts. Moreover, Hispanics who had been residents of the U.S. for less than five years were more likely to have misconceptions regarding $\mathrm{HCV}$ than individuals who have been living in the US for more than 5 years.

Our findings must be compared to others who have studied disparities in HCV knowledge. Buffington et al. [8] used mailed surveys with a $72 \%$ response rate to assess knowledge about HCV. Participants were selected by quota sampling, and stratified on demographic variables to represent
U.S. adults. Racial and ethnic minorities were oversampled. Although the Buffington study demonstrated disparities in knowledge among race groups, these findings may understate the true magnitude of the problem since undocumented immigrants and marginalized populations (without mailing addresses or phone numbers, for example) were not sampled. It has been estimated that unauthorized migrants accounted for $30 \%$ of the foreign-born population in 2005 [9]. Of the 11 million unauthorized migrants living in the United States, $78 \%$ are Latin America [9]. Such patients were captured in our patient population, thus increasing the generalizability of our data. These studies together, highlight the need for targeted educational campaigns that provide the community with information regarding HCV transmission.

A unique dimension of our study was an examination of differences in knowledge that exist between Hispanics born within and outside of the U.S. Not only have Hispanics become the largest minority in the U.S., but they also comprise the largest group of immigrants. Misconceptions about HCV transmission, may lead to high risk behavior and to infection among this growing population of immigrants. Related to this analysis was our finding that the level of knowledge was associated with the number of years of residency in the U.S. Specifically, those Hispanics with fewer years in the U.S. had less knowledge of HCV. The underlying reasons for this finding can only be conjectured upon. Perhaps the most likely possibility is that acculturation occurs with increasing exposure to high risk behaviors. Several studies have provided evidence to support this hypothesis [10]. For example, in a study conducted among Hispanic immigrants the authors found that a higher risk for obesity associated with length of residence may be due to acculturation processes such as the adoption of unhealthy dietary practice and sedentary lifestyles of the host country [11]. In addition, in a study conducted among Latino adolescents higher levels of acculturation were found to be associated with an increased likelihood of exhibiting problem behaviors (e.g. sex, alcohol/drug use) and a decreased likelihood of exhibiting certain health promoting behaviors (e.g. vitamin intake, personal hygiene, sleep habits) [12]. Importantly, our finding suggests that development of HCV prevention and education programs targeting recent Hispanic immigrants may have a great value in preventing HCV infection. The potential impact of such interventions is underscored by the fact that the immigrant Hispanic population is growing and projected to more than double by 2050 [13].

\section{ACKNOWLEDGEMENT}

Funding for this project was provided by an educational grant from Roche.

\section{REFERENCES}

[1] Armstrong GL, Wasley A, Simard EP, McQuillan GM, Kuhnert WL, Alter MJ. The prevalence of hepatitis $\mathrm{C}$ virus infection in the United States, 1999 through 2002. Ann Intern Med 2006; 144: 70514.

[2] Centers for Disease Control and Prevention. Recommendations for prevention and control of hepatitis $\mathrm{C}$ virus (HCV) infection and HCV-related chronic disease. MMWR 1998; 47.

[3] Seeff LB. Natural History of Hepatitis C. Am J Med 1999; 107 : 10S-15S.

[4] National Institutes of Health [NIH]. NIH Consensus Statement on the management of Hepatitis C: 2002. NIH Consensus and State of the Science Statements 2002; 19: 1-52. 
[5] Rawls RA, Vega KJ. Viral Hepatitis in Minority America. J Clin Gastroenterol 2005; 39(2): 144-150.

[6] Centers for Disease Control and Prevention. Summary of notifiable diseases: United States, 2001. MMWR 2003; 50: 1-99.

[7] Centers for Disease Control and Prevention. Hepatitis surveillance report no. 59, Atlanta, GA: U.S. Department of Health and Human Services, Centers for Disease Control and Prevention 2004.

[8] Buffington J, Damon S, Moyer L, Culver D. Racial differences in Knowledge regarding hepatitis C virus infection. JAMA 2000; 248: 1651-1652.

[9] Passel JS. The size and characteristics of the unauthorized migrant population in the U.S. Estimates Based on the March 2005 Current Population Survey. Pew Hispanic Center Research Report. (March 7, 2006) Retrieved from http: //pewhispanic.org/files/reports/61.pdf on Nov 11, 2006.
[10] Dev A, sundarahan V, Sievert W. Ethnic and cultural determinants influence risk assessment for hepatitis c acquistition. J Gastroenterol Hepatol 2004; 19: 792-8.

[11] Kaplan MS, Huguet N, Newsom JT, McFarland BH. The association between length of residence and obesity among Hispanic immigrants. Am J Prev Med 2004; 27(4): 323-326.

[12] Ebin VJ, Sneed CD, Morisky DE, Rotheram-borus MJ, Magnusson AM, Malotte CK. Acculturation and interrelationships between problem and health-promoting behaviors among latino adolescents. J Adol Health 2001; 28: 62-72.

[13] U.S. Census Bureau. U.S. Interim Projections by Age, Sex, Race and Hispanic Origin. 2004 Oct 24; [cited 2005 June 10]; Available from; http://census.gov/ipc/www/usinterimproj/. 